\title{
Enhancement Image Intensity of HSV Color Space
}

\author{
I Nyoman Gede Arya Astawa, I Ketut Gede Darma Putra, I Made Sudarma, Rukmi Sari Hartati
}

\begin{abstract}
One of factor that affects technology in face detecting or recognizing is illumination. Poor lighting can cause difficulty to the system to recognize face. Although it is over exposure or under exposure. By doing color image processing, it supports the system to detect face in a poor lighting condition. This research used lighting intensity normalization method to increase face detection performance. This method can normalize the light intensity especially on the face lighting. We normalize the light intensity through HSV color space. HSV color space has saturation which is amount of light in the image. The method proceed saturation in image to increase face detection performance. Total number of faces we had tested is 286 faces, the system detect 243 faces before intensity normalization proceed. Whereas, after normalization process, it detects more faces which is 279 faces. As we can see, the percentage improvement before to after intensity normalization is $84.97 \%$ to $97.55 \%$. This is $12.58 \%$ improvement. We can say this method helps face detection to increase it performance.
\end{abstract}

Keywords: face detection, intensity normalization, $\mathrm{HSV}$ color space.

\section{INTRODUCTION}

On these days, the face recognition system is a well-known research topic in the realm of computer vision, pattern recognition, and machine learning. These topics have been used extensively in the real world, for example, used for CCTV, criminal investigations, access control, content annotations within the website environment, etc. [1]. The rapid development of modern society has made more stringent requirements regarding the speed, accuracy and security of identity identification $[1,2]$. A Rapid biometric technology development makes it all possible. Among them, face detection and recognition are the most rapid. This method is much more straighforward and easier to use. [2]. In order to recognize the face in image, face detection need to be performed. Face detection system is a system that can locate human face position, size, and pose that contain in image. [3].

Integrated camera in mobile phone has been used to capture moment through image. Where, an image can contain many informations. Therefore, an image can be a valuable information if it processed through image recognition

Revised Version Manuscript Received on 10 September, 2019.

I Nyoman Gede Arya Astawa, Doctoral Programed of Engineering Science, Faculty of Engineering, Udayana University, Bali, Indonesia.(Email: arya_kmg@pnb.ac.id)

I Ketut Gede Darma Putra,, Department of Electrical Engineering, Politeknik Negeri Bali, Kampus Bukit Jimbaran, Kuta Selatan, Bali, Indonesia.

I Made Sudarma, Information of Technology, Faculty of Engineering, Udayana University, Bali, Indonesia..

Rukmi Sari Hartati, Electrical of Engineering, Faculty of Engineering, Udayana University, Bali, Indonesia. processing system such as face image. This process can be done because face image can provide specific information about personal identification and others [4].

One of factor that affects technology in face detecting or recognizing is illumination. [5]. Poor lighting can cause difficulty to the system to recognize face. Although it is over exposure or under exposure. By doing color image processing, it supports the system to detect face in a poor lighting condition.

This research had used intensity normalization method. According to [6], lighting can affect face detection performance. Lighting intensity normalization can increase the performance. So, normalization can be done on image, especially on the face lighting. This paper consist of background research and related researches that ever done had described in first and second section. In third section describe about intensity normalization. Also, fourth section describe about research result.

\section{RESEARCH METHOD}

Until now, it has been many studies talking about the lighting in an image. [7]. examine the increase of light intensity in an image. They focus on image that has not been degraded in low lighting. This is because the previous study conducted by [8] was considered to be failing to consider the image degradation factor causing the lost contrast not recoverable.

Other research that talked about lighting has been done by [6]. They used HSV color space where the color space is suitable to the intensity normalization rather than RGB color space. This is because HSV color space has saturation (illumination) and value (brightness).

We implement intensity normalization method to mobile device. This method proceed lighting in an image that contains more than one face.

Image processing had been done in few phases. At an early phase, image obtained from camera or can be loaded from existing image. Then, image converted from RGB to HSV color space. Next phase is normalizing the intensity. Last phase is convert back to RGB then detect all face. system flow had shown in figure 1.

HSV color space provide better histogram feature among other color spaces [9]. In HSV, there are 3 parts which are Hue (H), Saturation (S), dan Value (V) [10]. 


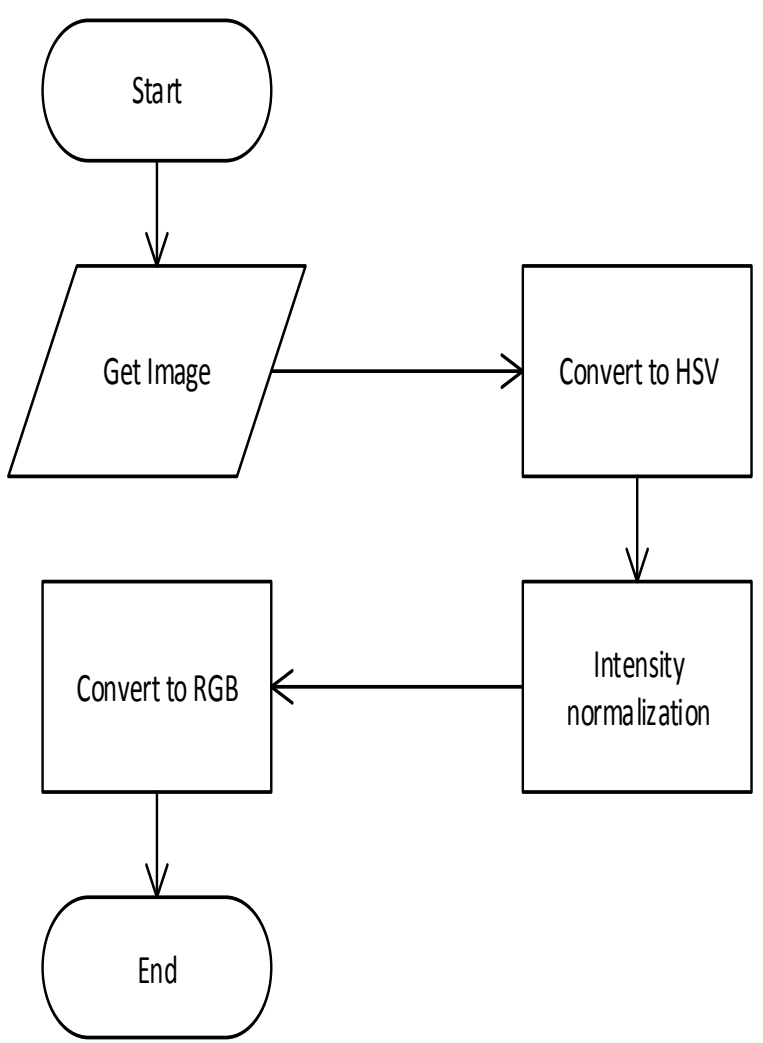

Figure 1. Global system flowchart

Hue has dominant color to be seen by viewer. Saturation refers to relative purity or amount of white light mixed with hue. Value refers to amount of black mixed with hue [11]. Equation to convert RGB to HSV shown in Equation 1,2, and 3.

$$
\begin{gathered}
V=\max (R, G, B) \\
S= \begin{cases}\frac{[V-\min (R, G . B)]}{V} & , \text { if } V \neq 0 \\
0 \quad & \text { if } V=0\end{cases} \\
H= \begin{cases}G-B \times \frac{60}{s} & \text {, if } V=R \\
240+(B-R) \times \frac{60}{s}, & \text { if } V=G \\
120+(R-G) \times \frac{60}{s}, & \text { if } V=B\end{cases}
\end{gathered}
$$

where $\mathrm{V}$ is value, $\mathrm{S}$ is saturation, $\mathrm{H}$ is hue, $\mathrm{R}$ is red value, $\mathrm{G}$ is green value, and $\mathrm{B}$ is blue value.

In this paper, we used multiface image for datasets. Where, image has been taken from social media, digital camera, and mobile phone. As for, we used Samsung Galaxy Tab for experimental device. Normalized detected image sample and its comparison shown in Figure 2.

\section{RESULTS AND DISCUSSION}

This part describes about experiment result using intensity normalization.

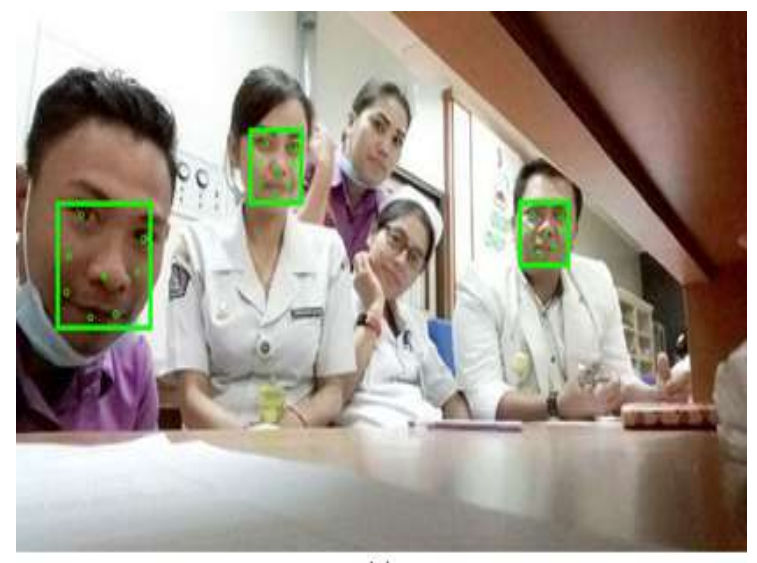

(a)

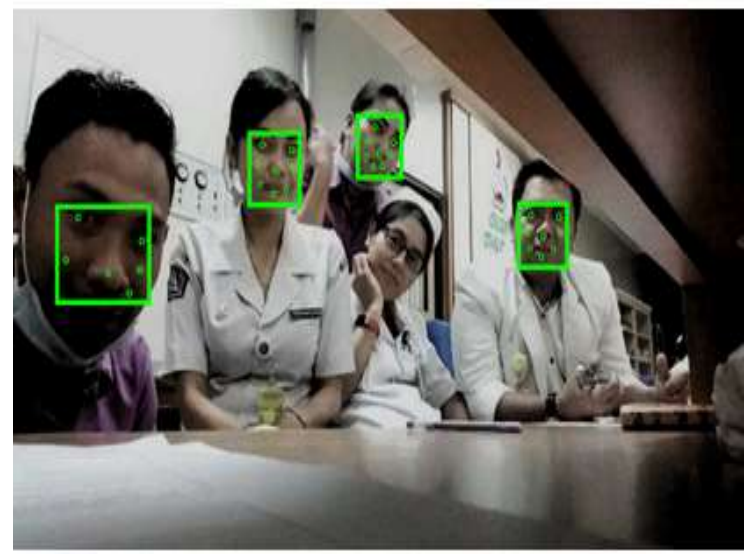

(b)

Figure 2. (a). Image before intensity normalization;

Figure 2(b). Image after intensity normalization

Based on Figure 2(a), it shown image before intensity normalization. Which is, only 12 faces that has been detected. Whereas, Figure 2(b) shown that 14 faces had been detected after intensity normalization process.

Absolute Mean Brightness Error (AMBE) proceed brightness level comparison in image. AMBE calculates differential of mean brightness between 2 images. When the AMBE value gets smaller, it means brightness level from both images more similar.

At Table 1, we test 109 data faces that had been taken from social media, 102 faces from phone camera, and 75 faces from digital camera. As for, the average AMBE value before normalization process is 18.05 . The AMBE value after intensity normalization process is 1.29 . We can see intensity normalization process can increase image lightness similarity level based on those values.

Table 1. Average AMBE value

\begin{tabular}{lccc} 
& $\begin{array}{c}\text { Number of } \\
\text { Face(s) }\end{array}$ & Before & After \\
\hline Social Media & 109 & 18.90 & 1.46 \\
\hline Phone Camera & 102 & 17.33 & 1.03 \\
\hline Digital Camera & 75 & 17.91 & 1.38 \\
\hline Average AMBE & & 18.05 & 1.29 \\
\hline
\end{tabular}


While, face detection before or after normalization test result can be seen on Table 2. Total number of faces is 286 faces. taken from social media as many as 109, 102 taken from camera phone, and digital camera as many as 75 faces.

Table 2. Face detection test result

\begin{tabular}{lccc} 
& Number of & \multicolumn{2}{c}{ AMBE } \\
& Face(s) & Before & After \\
\hline Social Media & 109 & 18.90 & 1.46 \\
\hline Phone Camera & 102 & 17.33 & 1.03 \\
\hline Digital Camera & 75 & 17.91 & 1.38 \\
\hline Average AMBE & & 18.05 & 1.29 \\
\hline
\end{tabular}

When look at the total number of faces which is 286 faces, the system detect 243 faces before intensity normalization proceed. Whereas, after normalization process, it detects more faces which is 279 faces. As we can see, the percentage improvement before to after intensity normalization is $84.97 \%$ to $97.55 \%$. This is $12.58 \%$ improvement.

\section{CONCLUSION}

Enhancement the intensity of facial images in the HSV color space provides excellent results on all devices. Experiments conducted by using the normalization method of intensity obtained AMBE value of 1.29 and the average increase in face detection of $12.58 \%$.

\section{ACKNOWLEDGMENTS}

The authors would like to express heartfelt thanks to the Prof. Dr. I Ketut Gede Darma Putra, S.Kom., MT, Dr. Ir. I Made Sudarma, M.A.Sc, Prof. Ir. Rukmi Sari Hartati, MT.Phd. Group for their helpful discussions. We also appreciate the Doctoral Programed of Engineering Science, Faculty of Engineering, Udayana University for supporting.

\section{REFERENCES}

1. Wang J-W, Le NT, Lee J-S, Wang C-C. 2016 Color face image enhancement using adaptive singular value decomposition in fourier domain for face recognition. Pattern Recognition.57:31-49.

2. Jun Z, Jizhao H, Zhenglan T, Feng W, 2017 20-22 Oct. 2017. Face detection based on LBP. 2017 13th IEEE International Conference on Electronic Measurement \& Instruments (ICEMI).

3. Wan L, Chen Pc, 2010 17-19 Dec. 2010. Face Detection Method Based on Skin Color and AdaBoost Algorithm. 2010 International Conference on Computational and Information Sciences.

4. Peng P, Shen Y, 2013 16-18 Dec. 2013. Efficient face verification in mobile environment using component-based PCA. 2013 6th International Congress on Image and Signal Processing (CISP).

5. Jiang X, Zhang D, Feng X, 2016 12-15 Dec. 2016. Local feature hierarchy for face recognition across pose and illumination. 2016 Sixth International Conference on Image Processing Theory, Tools and Applications (IPTA).

6. Al-Osaimi FR, Bennamoun M, Mian A, 2006 2006//. Illumination Normalization for Color Face Images. Advances in Visual Computing; (Berlin, Heidelberg).

7. Dong X, Wen J. 2016 Low lighting image enhancement using local maximum color value prior. Frontiers of Computer Science.10(1):147-56.

8. Bennett EP, McMillan L. 2005 Video enhancement using per-pixel virtual exposures. ACM Trans Graph.24(3):845-52.

9. Liu G-H, Yang J-Y. 2013 Content-based image retrieval using color difference histogram. Pattern Recognition.46(1):188-98.

10. Gonzalez RC, Woods RE. 2006. Digital Image Processing (3rd Edition): Prentice-Hall, Inc.

11. Lei T, Wang Y, Fan Y, Zhao J. 2013 Vector morphological operators in HSV color space. Science China Information Sciences.56(1):1-12. 